\title{
Análise da associação entre a imagem da mulher em comerciais de cerveja e o comportamento de compra dos consumidores
}

\author{
Analysis of the association between the woman's image in beer commercial \\ and consumer buying behavior
}

\author{
Monize Sâmara Visentini ${ }^{1}$ \\ Vanessa UnfriedFenner ${ }^{2}$ \\ Djeferson de Oliveira ${ }^{3}$
}

\begin{abstract}
Resumo
Desde o início do século XX, quando a bebida começou a surgir no país, até hoje, o principal atrativo dos comercias de cerveja consiste na imagem da mulher. Este estudo tem como objetivo verificar se esse consagrado atrativo realmente exerce influência sobre o comportamento de compra dos consumidores. Como metodologia, a pesquisa realizada foi descritiva e quantitativa, caracterizando-se como levantamento ou survey. Para possibilitar o alcance do objetivo proposto,aplicou-se um questionário auto administrado, validado por meio de um pré-teste com 309 consumidores de cerveja com idade superior a 18 anos. A amostra foi selecionada por meio de amostragem não probabilística por conveniência e com uma equação de Levine et al. (2013), utilizada em situações em que não se conhece o desvio-padrão amostral nem a proporção populacional do universo investigado. Como resultado da pesquisa, verificou-se a eficácia da imagem da mulher em propagandas de cerveja, especialmente diante do público masculino. Além disso, nota-se uma tendência de as consumidoras mulheres terem uma percepção mais positiva sobre comerciais de cerveja que ilustradas com homens.
\end{abstract}

Palavras-chave: Cerveja. Imagem da mulher. Comportamento de compra. Comportamento do consumidor.

\begin{abstract}
The woman image is the main beer commercial appeal, since the beginning of XX century, when the beverage first appeared on the country, till these days. Therefore, the following study aimed to verify if these established appeal really influence the consumer's purchase behavior. As methodology, the research is characterized as a descriptive and quantitative survey. To reach the goals of this study, it was applied a self-administered questionnaire, validated though a pretest, with 309 beer consumers older than 18 years. Sample was selected using a non-probabilistic convenience sampling, by Levine's et al. (2013) equation, used in situations where either the standard deviation or the portion of the population investigated is unknown. As results, it was attested the efficiency of woman image on beer commercials, especially in face of the masculine consumers. Moreover, it is noted a tendency regarding a positive perception from the feminine consumers when faced with commercials that show men models.
\end{abstract}

Keywords: Beer. Woman Image. Purchase Behavior.Consumer Behavior.

\section{Introdução}

Até a década de 80, o setor cervejeiro brasileiro baseava-se na primazia de duas grandes marcas: a Brahma e a Antarctica,quando deu-se início a um processo de reestruturação no país, com o surgimento de novas indústrias que ocupariam um lugar de destaque no mercado do ramo. Na primeira metade da década seguinte, o Brasil já era reconhecido mundialmente pela produção da bebida (SILVA, 2008).

\footnotetext{
Doutora em Administração pela Universidade Federal do Rio Grande do Sul (PPGA-EA-UFRGS). Professora Adjunta da Universidade Federal da Fronteira Sul (UFFS). Brasil. Afiliação: Universidade Federal da Fronteira Sul (UFFS)- Campus Cerro Largo. Lattes: http://lattes.cnpq. br/6482101738421142 Email: monize.visentini@uffs.edu.br

2 Graduação em Administração pela Universidade Federal da Fronteira Sul (UFFS). Brasil. Afiliação: Universidade Federal da Fronteira Sul (UFFS). Lattes: http://lattes.cnpq.br/0421301024859704 Email: va.fenner@hotmail.com

3 Graduação em Administração pela Universidade Federal da Fronteira Sul (UFFS). Brasil. Afiliação: Universidade Federal da Fronteira Sul (UFFS). Email: djefer@live.com
} 
A luta concorrencial, nessa e em outras indústrias, exige das empresas um maior conhecimento sobre o comportamento de compra do consumidor, já que, conforme Kotler (2000), uma empresa ganha dinheiro quando satisfaz as necessidades dos consumidores de forma superior aos seus concorrentes.

As companhias cervejeiras, com o intuito de as ações da concorrência,esforçam-se para produzir uma bebida que agrade aos consumidores por seu paladar e, assim, que consiga conquistar sua fidelidade (SILVA, 2008). Porém testes cegos realizados com consumidores (URDAN; URDAN, 2001) já comprovaram que está cada vez mais difícil associar uma marca ao seu sabor, pois os produtos estão se tornando mais semelhantes no aspecto visual, espuma e cor e sabor.

No setor cervejeiro, a preferência do consumidor costuma estar mais associada à imagem da marca e ao valor simbólico do produto (SILVA, 2008). Em virtude disso, as empresas precisam de significativos investimentos em marketing para criar marcas fortes e diferenciadas, capazes de atrair e despertar 0 desejo do público-alvo de seu produto.

O uso de publicidade, particularmente mediante comerciais impressos ou de televisão, sempre ocupou um importante espaço na indústria de cervejas do país. A publicidade se constitui em um meio de propagação de informações sobre determinados produtos ou serviços com objetivo despertar o interesse e o desejo pelo que é anunciado (GUAZINA; GUIMARÃES, 2016), sendo que, no contexto em discussão, enfoca-se a representação do corpo feminino, desde o início do século XX, quando a bebida começou a surgir no Brasil, até hoje.

Apropaganda auxilia na diferenciação de um negócio ou marca, podendo ser utilizada estrategicamente pelas empresas (BRANDÃO et al., 2016). É uma eficaz ferramenta, capaz de criar personalidade para uma marca, fazendo com que seja mais respeitada, desejada e consumida do que outras (BELCH; BELCH, 2014). Para Plummer (2000) e Aaker (1997), as marcas podem ser caracterizadas por perfis de personalidade definidos por uma série de atributos, assim como os indivíduos. Na definição de Plummer (1985), são três as dimensões que abarcam uma marca:sua personalidade, percebida pelo consumidor; e as outras duas são os atributos físicos e funcionais. Na perspectiva de Aaker (1997), a personalidade da marca é definida como um conjunto de características humanas que Ihe são associadas, sendo descritas pela autora por uma estrutura composta por cinco grandes dimensões (big five): sinceridade, agitação, competência, sofisticação e robustez. Foi a partir desse estudo que a investigação da personalidade da marca passou a ganhar destaque, sendo analisada sob diferentes perspectivas (GROHMANN, 2009).

Portanto, a percepção e o uso simbólico da marca por parte dos consumidores pode se dar através da visualização dos traços de sua personalidade, que é dependente daquilo que a empresa expõe e demonstra ser diante do mercado. Na concepção de Aaker (1997), diversos elementos possibilitam relacionar e direcionar a personalidade à uma marca, tais como as propagandas, símbolos, logos, preços, canais de comunicação, sendo por meio desses elementos que os consumidores irão se identificar com uma marca e preferi-la, quando comparadas aos concorrentes. A utilização desses elementos pode refletir a maneira como as empresas buscam persuadir os consumidores, conquistando-os para si, e até mesmo estabelecendo vínculos de fidelidade, procurando criar valores e provocar sensações por eles desejadas.

Considerando as propagandas e os comerciais, especificamente, para instigar sentimentos, as empresas do setor cervejeiro utilizam-se de diversos artifícios, com destaque para a imagem da mulher. Isto se deve, para Costa e Cavalcante (2007), à associação do consumo de cerveja com as sensações de liberdade, prazer e diversão. A eficácia do uso de tal recurso, no entanto, ainda não foi comprovada. Ademais, o mercado de cervejas tem sofrido algumas modificações advindas do crescimento do número de consumidoras mulheres. As principais marcas do ramo vêm buscando incluir a mulher como parte do público atuante e têm reduzido os comerciais que as representam como um produto de consumo, um objeto, ou fetiche associado à bebida (BORGES; CUNHA, 2015). Tanto a inexistência de estudos que investigam o efeito da utilização da imagem da mulher nos comerciais de cerveja como as mudanças que vêm ocorrendo no setor cervejeiro, em especial referente ao público consumidor de cerveja, tornam relevante a realização desta pesquisa e dão origem à seguinte questão: Aimagem da mulher nos comerciais de cerveja influencia o comportamento de compra dos consumidores deste produto? Desta maneira, esta pesquisa teve como principal objetivo verificar se a imagem da mulher em comerciais de cerveja influencia 
o comportamento de compra dos consumidores. Para possibilitar o alcance de tal objetivo, traçaram-se também três objetivos específicos:

1) Apontar as preferências dos consumidores quanto às marcas de cerveja;

2) Identificar a influência de fatores paralelos à imagem da mulher que atuam sobre o processo de decisão de compra dos consumidores de cerveja; e

3) Comparar a influência da imagem da mulher em comerciais de cerveja entre consumidores do sexo feminino e consumidores do sexo masculino.

Os resultados dessa pesquisa poderão ser úteis para a melhor compreensão do processo de comportamento de compra dos consumidores, a fim de que as organizações, utilizando-se do desenvolvimento estratégias e táticas de marketing, sejam capazes de atender mais adequadamente os desejos e necessidades dos consumidores. Outro fator que torna este estudo relevante é a sua capacidade de fornecer informações importantes para a comunidade acadêmica, contribuindo para a formação de novos profissionais e embasando novas pesquisas.

\section{0 mercado brasileiro de cervejas}

A cerveja é a bebida alcoólica mais consumida pelos brasileiros (IBOPE, 2013). O Brasil, em nível internacional, é o terceiro maior consumidor da bebida, atrás somente dos Estados Unidos e da China. No que se refere à produção, o Brasil também se encontra no topo do ranking, novamente ocupando a terceira posição, após China e Estados Unidos.

A produção de cerveja iniciou aqui no século XIX e, a partir daí, impulsionou o desenvolvimento de um setor que hoje promove uma das maiores contribuições econômicas para o país (SINDICERV, 2016). O conceito de marca para indústrias cervejeiras, no Brasil, contudo, estabeleceu-se apenas após a terceira década do século XX, mesmo período em que as empresas Brahma e Antarctica começam a se destacar no país (FERRARI, 2008).Na segunda metade dos anos 90, o Brasil passou a ocupar o quinto lugar na produção mundial de cerveja (OLIVEIRA; MEDEIROS; RIBEIRO, 1996).

Nos últimos anos do século $X X$, as principais marcas nacionais - Brahma e Antarctica - uniram-se em um processo de fusão, do qual nasceu a Companhia de Bebidas das Américas - AmBev. A multinacional era a terceira maior indústria cervejeira e a quinta maior fabricante de bebidas no mundo. Em 2004, uma nova fusão, entre a AmBev e a Interbrew, cria a InBeve a torna a líder do setor (ROSA; CONSENSA; LEÃO, 2006). Quatro anos mais tarde, a InBev adquiriu também a grande empresa americana Anheuser Bush (proprietária das reconhecidas marcas Budweiser e Stella Artois), configurando-se como a maior cervejaria do mundo e passando a se chamar, a partir de então,ABInBev (EXAME, 2008). Recentemente, em 2015, houve outra aquisição. A líder $A B$ InBev comprou a segunda maior empresa do setor no cenário mundial, a SABMiller $(G 1,2015)$. No cenário nacional atual, a AmBev, do grupo AB InBev, também é a maior empresa do setor, com aproximadamente $70 \%$ de participação no mercado (CERVIERI Jr. et al., 2014).

A principal mudança no setor, nos últimos anos, deu-se pelo aumento da oferta, tanto de tipos quanto de marcas de cerveja. A diversidade de tipos e marcas está relacionada ao raciocínio de Hooley, Piercy e Nicoulaud (2011), que afirmam que, à medida que os produtos ou serviços oferecidos por uma empresa tornam-se mais heterogêneos, tanto mais heterogêneos e mais diferenciados serão os seus concorrentes e tanto mais complexa será a competitividade.

Diante de um mercado de ampla concorrência e de grande variedade de marcas de produtos, como o mercado cervejeiro, uma empresa sente-se obrigada a adotar estratégias que a façam superar as demais de seu ramo. Surge, então, a necessidade de conhecer o mercado e os concorrentes para aplicar estratégias adequadas e capazes de dar à organização um desempenho eficaz.

\section{Estratégia de comunicação: a mulher nas propagandas de cervejas}

A fim de otimizar as vendas, aumentar lucros e atingir metas específicas, os profissionais de marketing utilizam estratégias de comunicação, disseminando as vantagens de seus produtos (CHURCHILL; PETER, 
2010). A propaganda é uma das formas utilizadas pelas empresas para se comunicar com seus clientes e consumidores em potencial (HOOLEY; PIERCY; NICOULAUD, 2011). Kotler e Armstrong (2007, p. 357) se referem à propaganda como um dos elementos do mix de comunicações de marketing ou mix de promoção e a definem como "qualquer forma paga de apresentação e promoção não pessoais de ideias, bens ou serviços com um patrocinador identificado".

A propaganda tem como função não só comunicar os atributos de um produto, mas também persuadir seu público a adquiri-lo (KIM, 2010). Os produtores de propagandas se utilizam de artimanhas como forma de embasar o procedimento de veiculação, aceitação e recepção de suas ideologias (GOMES; TOURINHO, 2015). Nesse sentido, diferentes produtos são associados a diferentes públicos. As marcas de cerveja, especificamente, tendo um público majoritariamente masculino, comumente utilizam artifícios relacionados à imagem feminina.

O uso da imagem feminina como estratégia de divulgação de cervejas não é novidade. A imagem da mulher está presente desde as primeiras campanhas nacionais, que eram baseadas nas campanhas europeias. "Os primeiros cartazes de Brahma e Antarctica nem pareciam propaganda de produto brasileiro. Desenhados por europeus, estampavam mocinhas de bochechas rosadas e chapéus exóticos. " (GRANATO; VILLELA, 1999, p. 135). Com o passar do tempo, as propagandas foram adquirindo as formas da população. "Hoje, o país tem uma identidade mais definida e as cervejas esforçam-se para se associar a ela. As bochechas alemãs foram substituídas por futebol, praia, sol, biquíni e pele morena. " (GRANATO; VILLELA, 1999, p. 135).

Segundo Momo e Franco (2013), a propaganda faz com que o produto vendido conquiste a confiança do consumidor, fazendo-o ilusoriamente identificar-se com o produto. No caso da cerveja, a mulher é relacionada diretamente ao produto, caracterizando e dando suas atribuições a ele. Assim, os desejos e fantasias do consumidor, na publicidade, são associados à figura feminina para que se concretize o consumo do produto (MOMO; FRANCO, 2013). Cruz (2008, p. 160) explica a utilização da imagem feminina como artifício dos comerciais de cerveja:

A cerveja por ela mesma não cria no imaginário social um poder de venda, é necessário ela estar associada a outros valores (atribuídos nesse caso à mulher) para se tornar um objeto de desejo e consumo. Aparecendo ao lado de objetos de consumo, os corpos femininos prometem um paraíso erótico, em suma, são, para nós, os representantes genéricos do que é desejável.

Para Rockenbach (2009), as propagandas de cerveja visam atingir principalmente o público masculino, e por isso utilizam imagens femininas para seduzir e, ao mesmo tempo, reforçar o papel das mulheres como objetos sexuais, subordinadas aos desejos do homem. Dessa forma a autora afirma que o apelo sexual tem se tornado um recurso atrativo para chamar a atenção do público para o produto. Segundo Malta e Silva (2016), apesar de a mulher receber destaque em muitos comerciais de cerveja, a sua apresentação como consumidora é modesta, prevalecendo uma representação que a caracteriza para compor o imaginário masculino.

Warmling e Barragan (2012) também percebem a propaganda como um meio de seduzir o cliente, fazendo com que ele seja consumidor de um determinado produto, ainda que esse consumo não seja por uma necessidade. Assim, afirmam que a mídia funcionou como um mecanismo de grande relevância na composição do imaginário que se formou em torno das mulheres. É a imagem da mulher desnuda e sensual que aguça os sentidos, modelando a imaginação e revelando uma força para convencer o públicoalvo.Uma força que, muitas vezes, a linguagem verbal por si só não consegue transmitir.

\section{Metodologia}

Com o intuito de constatar a influência da imagem da mulher em comerciais de cerveja, esta pesquisaé definida, quanto aos objetivos,segundo Vergara (2000),como descritiva,pois apresenta as características de determinada população ou fenômeno em estudo, estabelece correlações entre variáveis e define sua natureza. As pesquisas descritivas utilizam como método os levantamentos, a análise qualitativa de dados 
secundários, a observação e os painéis, podendo ser classificadas como transversais e longitudinais (MALHOTRA, 2012). A presente pesquisa consiste em um estudo de levantamento transversal único, envolvendo a extração de dados de uma determinada amostra da população durante um único período de tempo.

Quanto à natureza ou abordagem, esta pesquisa é considerada quantitativa, pois considera uma busca quantificável e mensurável (SILVA; MENEZES, 2001). Isto significa traduzir para a forma numérica as opiniões encontradas e informações coletadas para classificá-las, tratá-las e analisá-las por meio da aplicação de um questionário, com respostas fechadas. Dessa forma, a pesquisa terá por base o método de levantamento ou survey. Os levantamentos consistem em "entrevistas com muitas pessoas por meio de questionários predeterminados" (MALHOTRA, 2012, p. 90). Aaker, Kumar e Day (2011) consideram o levantamento como o método mais adequado para a coleta de dados de pesquisas descritivas. Outra justificativa reside no fato de que este estudo busca analisar o comportamento de compra dos consumidores com relação à influência da imagem da mulher e, segundo Malhotra (2012), o método de levantamento, dentre outros fins, é utilizado para examinar o comportamento de compras e consumo.

Os levantamentos são o meio mais flexível de obter dados e informações a respeito dos motivos, das atitudes e das preferências dos consumidores. Segundo Malhotra (2012), o método de levantamento permite que os dados coletados sejam manipulados de diversas maneiras, possibilitando ao pesquisador determinar as diferenças entre dois grupos e analisar os efeitos de variáveis independentes. Nesta pesquisa, busca-se verificar a relação entre a variável imagem da mulher em propagandas e comerciais de cervejas e o comportamento de compra dos consumidores desse produto. Este estudo, além de quantitativo, caracteriza-se como transversal único, pois, segundo Malhotra (2012, p. 62), nesses estudos "é extraída da população-alvo uma amostra de entrevistados e as informações são obtidas dessa amostra somente uma vez".

Para determinar a amostra da pesquisa, composta por consumidores de cerveja com idade igual ou superior a 18 anos, foi utilizada a amostragem não probabilística por conveniência. De acordo com Malhotra (2012, p. 275), a amostra não probabilística consiste em "uma técnica que procura obter uma amostra de elementos convenientes. A seleção das unidades amostrais é deixada a cargo do entrevistador".

Os dados da amostra foram obtidos com a aplicação de um questionário, instrumento típico do survey utilizado neste estudo, elaborado pelos autores com base na revisão de literatura sobre o assunto em estudo e dividido em três blocos. O primeiro e o segundo blocos continham questões referentes ao perfil do respondente e suas características enquanto consumidor de cerveja respectivamente. Já o terceiro bloco apresentou uma escala Likert visando mensurar a percepção dos consumidores sobre doze diferentes imagens publicitárias. Para cada imagem,os respondentes atribuíram uma nota de 1 a 5 pontos, sendo a menor nota a mais negativa e, por sua vez, a maior a mais positiva. As imagens utilizadas foram encontradas na internet e editadas para a remoção do nome ou logotipo das marcas de cerveja. Esse procedimento foi realizado a fim de evitar que a percepção dos respondentes fosse influenciada pela marca da cerveja, e não somente pelos seus conteúdos.

A aplicação do instrumento ocorreu de modo virtual:convites contendo o link do questionário foram enviados ao público investigado via e-mail, utilizando a abordagem de bola de neve, ou seja, contemplando a indicação dos respondentes como critério de seleção mútua. Assim, um entrevistado sugere/indica outro com mesmo perfil e, dessa forma, caracteriza a bola de neve. O número de participantes da amostra foi estimado conforme a equação (1) de Levine et al. (2013), utilizada em situações em que não se conhece o desvio-padrão amostral nem a proporção populacional do universo investigado. Utilizando-se a equação e considerando-se um nível de confiança de $90 \%$, cujo valor crítico é 1,645, e um erro estimado de $5 \%$, obtêm-se uma amostra composta por 271 indivíduos consumidores de cerveja com idade igual ou superior a 18 anos. 


$$
\begin{aligned}
& \text { Equação } 1 \text { - Cálculo amostral } \\
& n=\frac{\left[z_{\alpha / 2}\right]^{2} \cdot 0,25}{E^{2}}=\frac{1,645^{2} \cdot 0,25}{0,05^{2}}=270,6=271
\end{aligned}
$$

Fonte: Elaborado pelos autores (2016).

A fim de validar o instrumento de pesquisa, foi realizado um pré-teste de modo presencial com 23 acadêmicos de um curso de Administração, que, assim como o público-alvo do estudo, caracterizam-se como consumidores de cerveja. Esse procedimento teve por objetivo identificar e eliminar problemas do instrumento de coleta, possibilitando sua reformulação e tornando-o apto a ser aplicado para a real amostra investigada. A escolha da população do pré-teste fundamentou-se na ideia de Gil (2010), que afirma que o teste piloto deve ter a participação da população o mais similar possível daquela que efetivamente constará na pesquisa.Os resultados obtidos com o pré-teste indicaram a necessidade de inclusão e exclusão de algumasalternativas em duas questões referentes ao perfil dos respondentes sob a condição de consumidores de cerveja. Após essesajustes, o questionário foi elaborado em meio virtual e enviado atrês indivíduos, também com as características da amostra, para uma nova validação. Avalidação indicou somente a necessidade de modificação da redação de uma alternativa de uma questão integrante do segundo bloco do questionário. Finalmente, feitos todos os ajustes necessários, o instrumento de coleta foi enviado à amostra efetiva do estudo.

Para a análise dos resultados, foram utilizados os softwares de apoio Microsoft Excel e o software livre de estatística R. O primeiro foi utilizado para a tabulação e codificação dos dados, enquanto o segundo serviu de suporte para a realização das análises estatísticas. Tais análises envolvem estatística descritiva, teste qui-quadrado e teste t para amostras independentes. $O$ teste qui-quadrado foi utilizado para analisar a existência de uma relação de influência entre o sexo dos consumidores e os motivos que os levam a escolher uma determinada marca de cerveja. $O$ teste foi realizado apenas para a análise dessasvariáveis devido à importancia delas para o alcance do objetivo proposto. Já o teste t para amostras independentes foi utilizado com o intuito de verificar a existência de diferença significativa entre as médias de notas atribuídas às imagens pelos grupos feminino e masculino. Por meio deste teste, torna-se possível afirmar com maior consistência qual dos grupos apresentou percepções mais positivas sobre imagens que continham mulheres.

\section{Análise e discussão dos resultados}

A amostra da pesquisa foi composta por 309 consumidores de cerveja, com idade igual ou superior a 18 anos. Deste total, verificou-se que $51,5 \%$ são mulheres e $48,5 \%$ são homens, o que indica um equilíbrio entre os gêneros e assegura uma maior confiabilidade nos resultados do estudo.Em relação à idade dos consumidores participantes da pesquisa, obteve-se uma média de 28,84 anos. Para facilitar a análise referente à idade dos respondentes, optou-se por agrupar grupos etários em quartis. Para isso, determinouse a idade mínima e a máxima, 18 e 64 anos respectivamente. A partir disso, verificou-se, conforme o gráfico 1, que, apesar de haver relativo equilíbrio entre as faixas etárias, os consumidores com idades de 18 a 21 anos compõem a maior parte dos respondentes, com um percentual de $29,55 \%$. 


\section{Gráfico 1 - Idade dos consumidores}

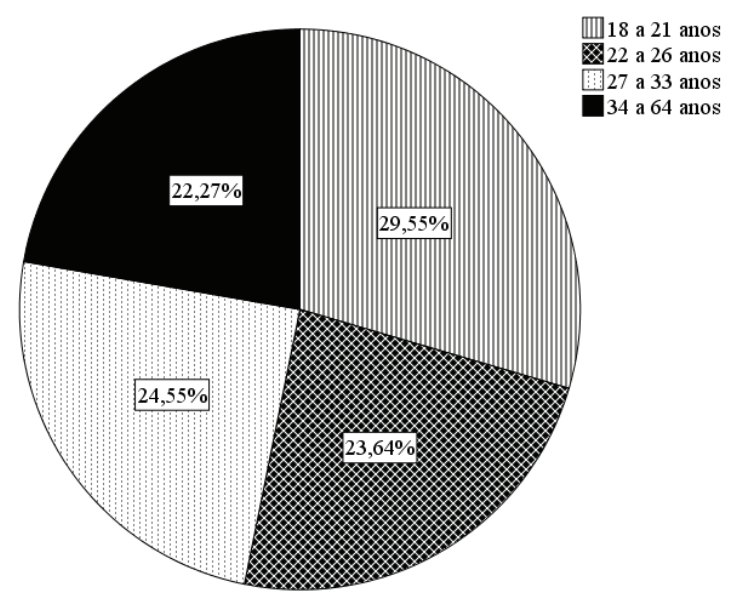

Fonte: Elaborado pelos autores (2016).

Embora permitisse a inclusão de consumidores de todo o país, a amostra da pesquisa atingiu apenas nove estados brasileiros, com destaque para o Rio Grande do Sul $(45,60 \%)$ e Santa Catarina $(45,60 \%)$, que juntos representam $91,2 \%$ do total de respondentes. Os demais estados encontrados foram Rio de Janeiro, Paraná, Paraíba, Minas Gerais, São Paulo e Espírito Santo, além do Distrito Federal, conforme a tabela 1.

Tabela 1 - Estados atingidos pela pesquisa

\begin{tabular}{lcc}
\hline Estado & N & Porcentual \\
\hline Santa Catarina (SC) & 141 & $45,60 \%$ \\
Rio Grande do Sul (RS) & 141 & $45,60 \%$ \\
Paraná (PR) & 6 & $1,90 \%$ \\
Rio de Janeiro (RJ) & 6 & $1,90 \%$ \\
Paraíba (PB) & 5 & $1,60 \%$ \\
Minas Gerais (MG) & 4 & $1,30 \%$ \\
São Paulo (SP) & 3 & $1 \%$ \\
Distrito Federal (DF) & 2 & $0,60 \%$ \\
Espírito Santo (ES) & 1 & $0,30 \%$ \\
\hline Total & 309 & $100 \%$ \\
\hline
\end{tabular}

Fonte: Elaborada pelos autores (2016).

Em relação ao tempo de consumo da cerveja, observou-se que, de modo geral, os consumidores fazem uso da bebida há pouco tempo, pois mais da metade dos respondentes (56,37\%) afirmaram serem consumidores há menos de 10 anos. Quanto à frequência do consumo, quase $46,9 \%$ dos consumidores bebem cerveja apenas em finais de semana, e 35,6\% consomem a bebida apenas em festas (tabela 2). Vale notar ainda,conformeatabela2, que apenas dois consumidores, o que representa somente $0,6 \%$ do total, afirmaram ingerir a bebida todos os dias. 
Tabela 2 - Frequência do consumo de cerveja

\begin{tabular}{lcc}
\hline Frequência & $\mathbf{N}$ & Porcentual \\
\hline Apenas em finais de semana & 145 & $46,9 \%$ \\
\hline Apenas em festas & 110 & $35,6 \%$ \\
Pelo menos três dias por semana & 48 & $15,5 \%$ \\
De três a seis dias por semana & 4 & $1,3 \%$ \\
Todos os dias & 2 & $0,6 \%$ \\
\hline Total & 309 & 100 \\
\hline
\end{tabular}

Fonte: Elaborado pelos autores (2016).

Do total de 309 consumidores que compuseram a amostra, 220 assumiram ter preferência por uma marca específica e consumi-la com maior frequência. A partir disso, foram investigadas as marcas com maior índice de preferência entre os consumidores, evidenciando as diferentes preferências entre homens e mulheres, bem como os motivos que os levam a optar pela marca. As marcas de preferência dos consumidores que afirmaram consumir uma marca mais frequentemente foram Brahma (29,5\%) e Budweiser (20\%). A preferência pela marca Brahma também foi verificada por Oliveira e Gonçalves (2014), que investigaram o comportamento de compra de consumidores de cerveja universitários. Também foi possível verificar que tanto homens quanto mulheres indicaram a Brahma como marca consumida com mais frequência (Tabela 3). No entanto, a marca foi escolhida por um número maior de mulheres (40) do que de homens (25).

Tabela 3 - Marcas de preferência por sexo

\begin{tabular}{lccc}
\hline \multirow{2}{*}{ Marca } & \multicolumn{2}{c}{ Sexo } & Total \\
\cline { 2 - 3 } & Feminino & Masculino & 8 \\
\hline Antarctica & 7 & 1 & 65 \\
Brahma & 40 & 25 & 14 \\
Bohemia & 6 & 8 & 44 \\
Budweiser & 23 & 21 & 15 \\
Heineken & 5 & 10 & 7 \\
Kaiser & 4 & 3 & 9 \\
Stella Artois & 5 & 4 & 16 \\
Polar & 7 & 9 & 18 \\
Skol & 8 & 10 & 24 \\
Outras & 9 & 15 & 220 \\
\hline Total & 114 & 106 & \\
\hline
\end{tabular}

Fonte: Elaborado pelos autores (2016).

Quando questionados sobre as razões pelas quais têm preferência sobre determinada marca, podendo assinalar até três alternativas de resposta, os consumidores apontaram como principal motivo o sabor, que representou $57,6 \%$ do total de respostas (Tabela 4). Assim, entende-se que, quando têm a possibilidade de elencar fatores que motivam o consumo de determinada marca de cerveja, os consumidores tendem a indicar o fator sabor. Romero (2016) também identificou o sabor como o fator mais importante na escolha da marca de bebidas alcoólicas. Porém, Urdan e Urdan (2001) rejeitam a possibilidade de haver uma interferência do sabor na escolha de uma marca de cerveja a ser consumida. Mediante a realização de testes cegos, os autores provaram que o sabor não pode ser diferenciado de uma cerveja para outra. Concordando com os autores, Allison e Uhl (1964) identificaram que os consumidores de cerveja com preferências bem estabelecidas tendem a pontuar o gosto de sua marca preferida com nota significativamente mais alta quando a marca foi identificada do que durante o teste cego. 
Tabela 4 - Motivos de escolha da marca

\begin{tabular}{|c|c|c|c|}
\hline \multirow[b]{2}{*}{ Motivos } & \multicolumn{2}{|c|}{ Respostas } & \multirow{2}{*}{$\begin{array}{c}\text { Porcentagem de } \\
\text { casos }\end{array}$} \\
\hline & $\mathbf{N}$ & Porcentagem & \\
\hline Sabor & 198 & $57,60 \%$ & $90,00 \%$ \\
\hline Preço & 46 & $13,40 \%$ & $20,90 \%$ \\
\hline Indicações/influência de amigos & 43 & $12,50 \%$ & $19,50 \%$ \\
\hline Outros & 32 & $9,30 \%$ & $14,50 \%$ \\
\hline Marca & 25 & $7,30 \%$ & $11,40 \%$ \\
\hline Total & 344 & $100,00 \%$ & $156,40 \%$ \\
\hline
\end{tabular}

Fonte: Elaborado pelos autores (2016).

O preço $(13,4 \%)$ e as indicações e influências de amigos (12,5\%) também aparecem como fatores importantes para a escolha da marca. Percebe-se por meio desse resultado "a importância do fator social, seja na forma de recomendação de um amigo ou da pressão exercida pelos grupos"(TAGNIN; GIRALDI, 2013, p. 104). Além disso, esse fator revela a eficácia não apenas da comunicação de marketing, que envolve as propagandas e os comerciais, mas também do marketing boca a boca. Solomon (2016, p. 266) comprova a maior eficácia do marketing boca a boca perante as propagandas e comerciais afirmando que "como ouvimos informações de pessoas que conhecemos, o boca a boca tende a ser mais confiável que as recomendações que obtemos através dos canais de marketing formais".

A marca da cerveja é o motivo menos apontado como determinante da sua escolha, com apenas $7,3 \%$ do total de respostas. Resta ainda, dentre os principais motivos citados, a opção "Outros", que engloba o status que a marca proporciona, o design da embalagem, a atratividade das propagandas e comerciais veiculados, o aroma e a qualidade.

Afim de melhor compreender o comportamento dos consumidores de cerveja, realizaram-se análises cruzadas. A primeira dessas análises foi o cruzamento entre os motivos e o gênero sexual dos consumidores, o que pode ser visualizada na tabela 5 .

Tabela 5 - Motivos que levam homens e mulheres a escolher uma determinada cerveja

\begin{tabular}{lccc}
\hline \multirow{2}{*}{ Motivos } & \multicolumn{2}{c}{ Sexo } & Total \\
\cline { 2 - 3 } & Feminino & Masculino & \\
\hline Sabor & 100 & 98 & 198 \\
Marca & 11 & 14 & 25 \\
Preço & 23 & 23 & 46 \\
Indicações/influência de amigos & 27 & 16 & 43 \\
Outros & 13 & 19 & 32 \\
Total & 174 & 170 & 344 \\
\hline
\end{tabular}

Fonte: Elaborado pelos autores (2016).

É possível perceber que as mulheres, mais do que os homens, tendem a escolher a marca devido a indicações e influências sociais. Apesar disso, os motivos apontados pelos consumidores não apresentam grandes variações em relação ao gênero, o que pode ser comprovado com a realização do teste quiquadrado. Considerando-se que a hipótese nula $(\mathrm{H} 0)$ corresponde à inexistência de uma relação entre as variáveis sexo e motivos, e que $\mathrm{H} 1$ corresponde a sua existência, obtém-se $X$-squared=4,2732, df $=4$ e $p$-value $=0,3703$.Através do resultado de "p-value", superior a 0,05, a hipótese nula é aceita. Assim, pode-se afirmar que não existe relação de influência entre as variáveis sexo e motivos da preferência pela marca.

Assim como o sexo, a idade parece não influenciar o motivo de escolha de uma cerveja, principalmente entre consumidores que afirmam valorizar o sabor da cerveja, conforme consta na tabela 6. 
Tabela 6 - Motivos de preferência por idade

\begin{tabular}{|c|c|c|c|c|c|}
\hline \multirow{2}{*}{ Motivos } & \multicolumn{4}{|c|}{ Idade (anos) } & \multirow{2}{*}{ Total } \\
\hline & 18 a 21 & 22 a 26 & 27 a 33 & 34 a 64 & \\
\hline Sabor & $\begin{array}{c}58 \\
(26,4 \%)\end{array}$ & $\begin{array}{c}47 \\
(21,4 \%)\end{array}$ & $\begin{array}{c}49 \\
(22,3 \%)\end{array}$ & $\begin{array}{c}44 \\
(20,0 \%)\end{array}$ & $\begin{array}{c}198 \\
(90,0 \%)\end{array}$ \\
\hline Marca & $\begin{array}{c}8 \\
(3,6 \%)\end{array}$ & $\begin{array}{c}8 \\
(3,6 \%)\end{array}$ & $\begin{array}{c}6 \\
(2,7 \%)\end{array}$ & $\begin{array}{c}3 \\
(1,4 \%)\end{array}$ & $\begin{array}{c}25 \\
(11,4 \%)\end{array}$ \\
\hline Preço & $\begin{array}{c}18 \\
(8,2 \%)\end{array}$ & $13(5,9 \%)$ & $\begin{array}{c}8 \\
(3,6 \%)\end{array}$ & $\begin{array}{c}7 \\
(3,2 \%)\end{array}$ & $\begin{array}{c}46 \\
(20,9 \%)\end{array}$ \\
\hline Indicações/influência de amigos & $\begin{array}{c}19 \\
(8,6 \%)\end{array}$ & $\begin{array}{c}18 \\
(8,2 \%)\end{array}$ & $\begin{array}{c}5 \\
(2,3 \%)\end{array}$ & $\begin{array}{c}1 \\
(0,5 \%)\end{array}$ & $\begin{array}{c}43 \\
(19,5 \%)\end{array}$ \\
\hline Outros & $\begin{array}{c}6 \\
(2,7 \%)\end{array}$ & $\begin{array}{c}7 \\
(3,2 \%)\end{array}$ & $11(5,0 \%)$ & $\begin{array}{c}8 \\
(3,6 \%)\end{array}$ & $\begin{array}{c}32 \\
(14,5 \%)\end{array}$ \\
\hline Total & $\begin{array}{c}65 \\
(29,5 \%)\end{array}$ & $\begin{array}{c}52 \\
(23,6 \%)\end{array}$ & $\begin{array}{c}54 \\
(24,5 \%)\end{array}$ & $\begin{array}{c}49 \\
(22,3 \%)\end{array}$ & $\begin{array}{c}220 \\
(100 \%)\end{array}$ \\
\hline
\end{tabular}

Fonte: Elaborado pelos autores (2016).

É possível perceber que consumidores mais jovens tendem a escolher a marca a ser consumida devido à influência de amigos mais do que os consumidores mais velhos. Da mesma forma, também parecem ser os mais jovens os consumidores que mais levam em conta o preço e a marca do produto.

\subsection{Análise da percepção dos consumidores sobre as imagens publicitárias}

Os resultados sobre as percepções dos consumidores das imagens publicitárias foram obtidos por meio do teste $t$ para amostras independentes, realizado para cada imagem. Para os testes, foram consideradas as seguintes hipóteses:

(H0)Em média, homens e mulheres avaliam a imagem de maneira igual;

(H1)Em média, homens e mulheres avaliam a imagem de maneira diferente.

O resultado do teste para as 12 imagens pode ser verificado na figura 1 e na figura 2, além das médias de notas atribuídas por homens e mulheres para cada uma delas. 
Figura 1 - Testes das imagens publicitárias (parte I)
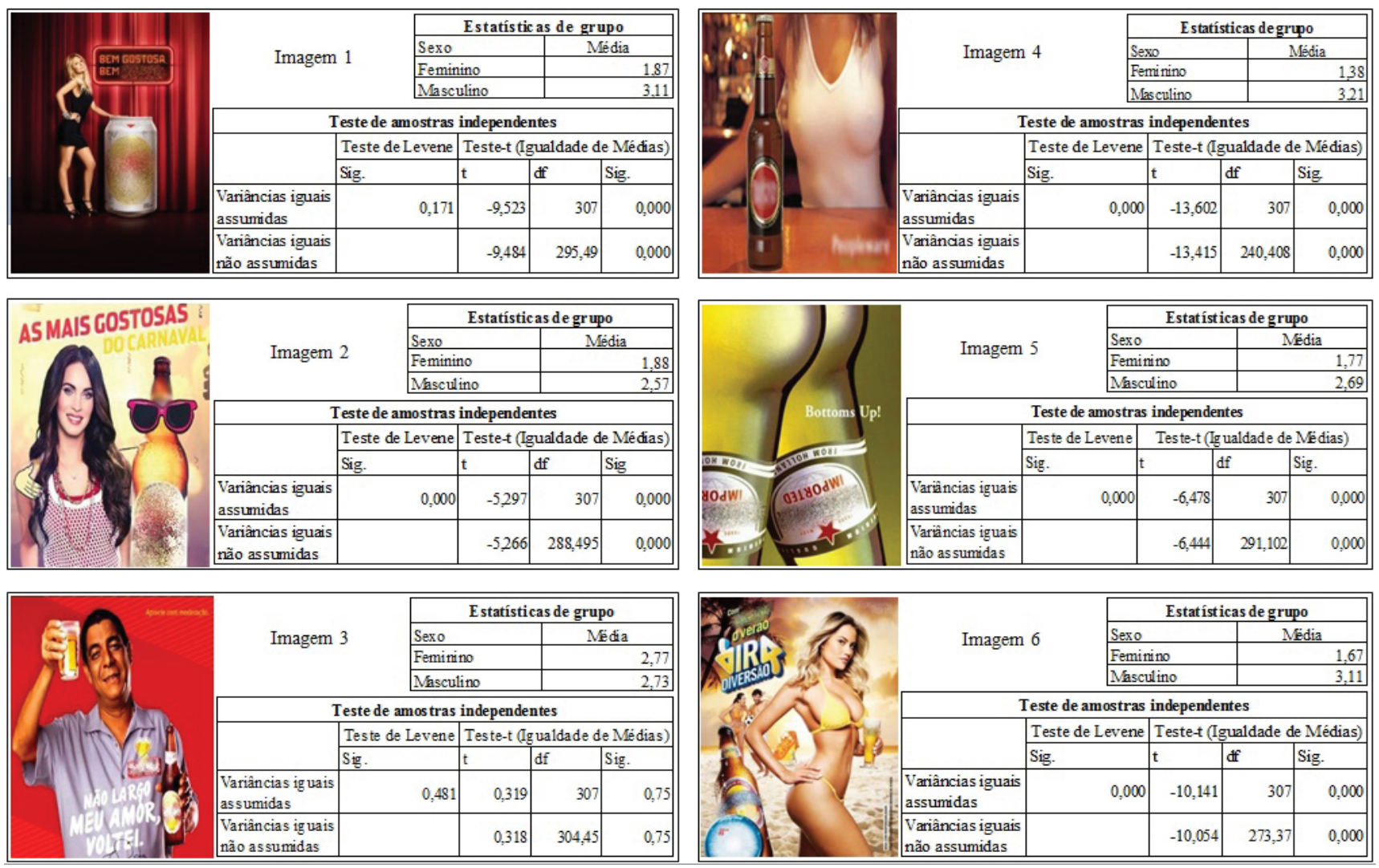

Fonte: Elaborada pelos autores (2016).

Figura 2 - Testes das imagens publicitárias (parte II)
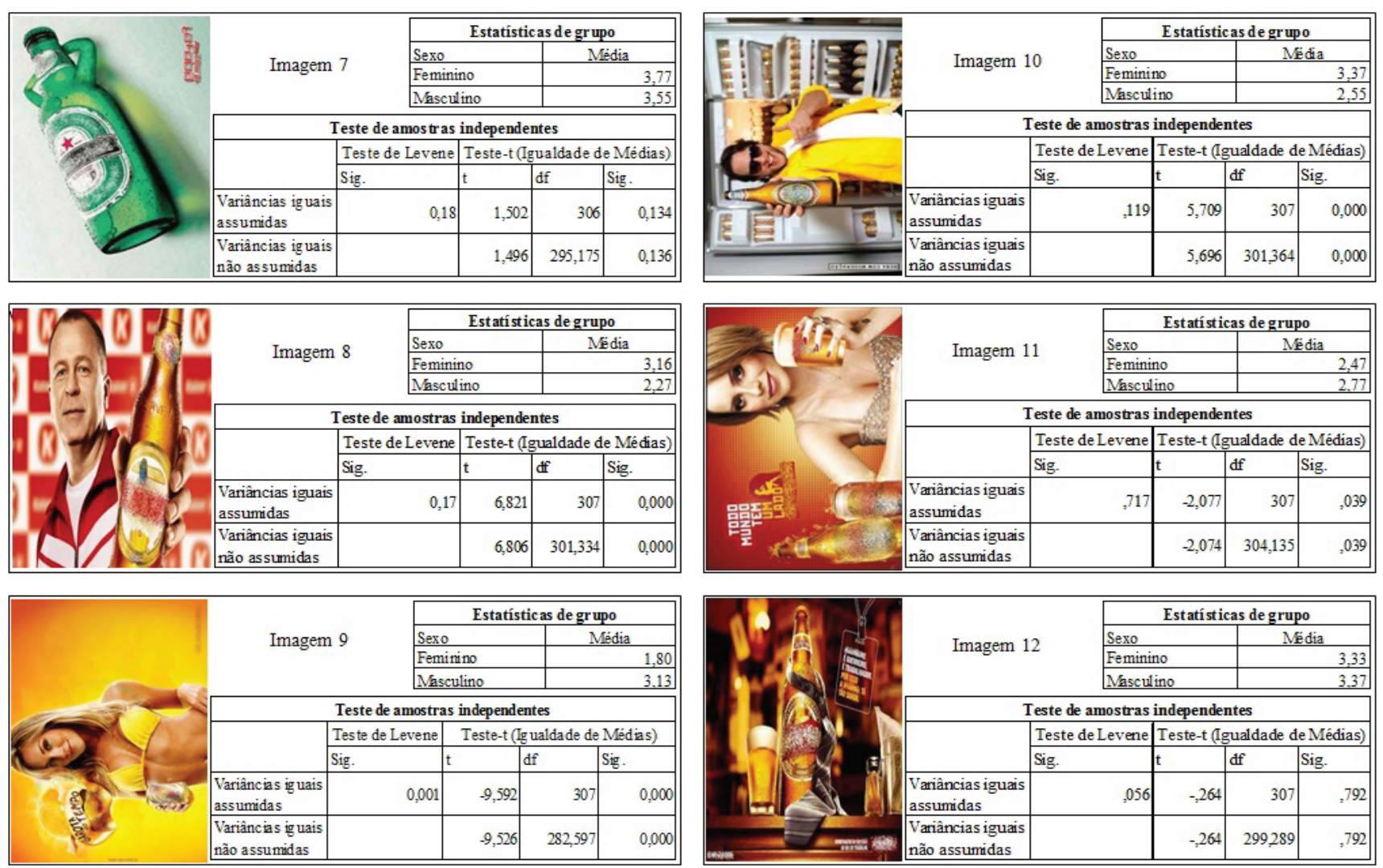

\begin{tabular}{|c|c|c|c|c|}
\hline \multirow{4}{*}{ Imagem 12} & & \multicolumn{3}{|c|}{ Estatísticas de grupo } \\
\hline & & \multicolumn{2}{|c|}{ Media } \\
\hline & Feminir & & \multirow{2}{*}{\multicolumn{2}{|c|}{$\begin{array}{r}3,33 \\
3.37 \\
\end{array}$}} \\
\hline & \multicolumn{2}{|c|}{ Masculino } & & \\
\hline \multicolumn{5}{|c|}{ Teste de amostras independentes } \\
\hline & Teste de Leven & \multicolumn{3}{|c|}{ Teste-t (Igualdade de Médias) } \\
\hline & \begin{tabular}{|l|} 
Sig. \\
\end{tabular} & $\mathrm{t}$ & df & Sig. \\
\hline $\begin{array}{l}\text { Variâncias iguais } \\
\text { assumidas }\end{array}$ & 056 &,- 264 & 307 &, 792 \\
\hline $\begin{array}{l}\text { Variâncias iguais } \\
\text { não assumidas }\end{array}$ & &,- 264 & 299,289 &, 792 \\
\hline
\end{tabular}

Fonte: Elaborado pelos autores (2016). 
Os testes de amostras independentes resultaram na rejeição da hipótese nula para as imagens 1, 2, 4, 5 e 6 (Figura 1) e para as imagens 8, 9, 10 e 11. Dessa forma, pode-se concluir que, em média, as notas atribuídas a essas imagens pelos homens e pelas mulheres são significativamente diferentes.

Nota-se que, dentre as imagens com médias de notas significativamente diferentes entre os grupos masculino e feminino, somente as imagens 8 e 10 não ilustram mulheres nem fazem alusão ao corpo feminino. Inversamente às demais, as duas imagens publicitárias ilustram homens. Pode-se perceber também, pelas estatísticas de grupo, que são as mulheres que atribuíram notas maiores aos dois comerciais. Esse resultado indica uma possível tendência de as consumidoras possuírem melhores percepções, e consequentemente serem mais influenciadas, por comerciais que exibem homens, da mesma forma que os homens mostram ter seu comportamento de compra mais facilmente influenciado por propagandas que ilustram mulheres, ou que se referem, mesmo que de forma subliminar, ao corpo feminino.

Já os testes para as imagens 3 (Figura 1), 7 e 12 (Figura 2) levaram à aceitação da hipótese nula, indicando que homens e mulheres avaliaram tais imagens de maneira igual. Quanto ao conteúdo das imagens em questão, tratam-se de comerciais com a presença de uma figura masculina reconhecida nacionalmente (Imagem 3) e de comerciais que ilustram o produto cerveja com apelo humorístico (Imagem 7) e em forma de homenagem ao público trabalhador (Imagem 12).

Em síntese, os resultados dos testes indicam que há uma percepção positiva dos consumidores sobre a imagem da mulher ou de apelos sexuais nos comerciais de cerveja. As imagens foram, na maioria, avaliadas de maneira mais positiva por consumidores do sexo masculino e mais negativa por consumidores do sexo feminino. As propagandas de cerveja buscam atingir principalmente os homens, que compõem a maior parcela do público consumidor do produto e, por isso, utilizam a imagem da mulher como forma de seduzir o público (ROCKENBACH, 2009). Petroll e Rossi (2008), em um estudo sobre apelos sexuais em propagandas, identificaram que os homens são menos favoráveis aos anúncios contendo modelos masculinos, principalmente com apelo sexual, e mais favoráveis aos anúncios contendo modelos femininos, que contém alto nível de apelo sexual.

Outro resultado interessante diz respeito à possível tendência das mulheres avaliarem de forma positiva imagens publicitárias que retratam homens. Das três imagens com tal característica $(3,8,10)$, somente uma (Imagem 3) não foi melhor avaliada por mulheres do que por homens. Tal resultado também vai de encontro às constatações de Petroll e Rossi (2008). Os autores perceberam que as mulheres eram mais favoráveis a propagandas com modelos masculinos e menos favoráveis aos que exibiam modelos do sexo feminino. Neste caso, no entanto, as consumidoras mulheres não se mostravam tão favoráveis aos altos índices de apelo sexual quanto os consumidores homens.

\section{Conclusão}

Por meio deste estudo é possível entender a importância da propaganda como um meio de seduzir o cliente, fazendo com que ele se torne consumidor de um determinado produto. Para tanto, as empresas utilizam mecanismos para tornar mais fácil convencer o público-alvo a consumir seus produtos. Nesta pesquisa, foram destacadas as propagandas de cerveja, que costumam utilizar-se da imagem de mulher como objeto de persuasão.

O principal objetivo pretendido, que também constitui a questão de pesquisa, confirmou a existência da influência do uso da a imagem feminina nos comerciais de cerveja sobre o comportamento de compra do consumidor homem, visto que as percepções de diferentes indivíduos quanto a diferentes propagandas foram variadas e considerando que,conforme Kotler e Armstrong (2007, p. 124) afirmam, a percepção definida por eles como "a forma pela qual uma pessoa seleciona, organiza e interpreta as informações para criar um quadro significativo do mundo" - é um dos fatores tidos como psicológicos que influenciam o comportamento de compra.

Constatou-se também que a marca mais consumida entre os consumidores pesquisados é a Brahma e que vários fatores estão envolvidos na decisão de compra, sendo o principal o sabor da cerveja. $O$ resultado, no entanto, se contrapõe ao de Urdan e Urdan (2001), que,por meio de um estudo contendo 
testes cegos, revelaram a impossibilidade de o sabor da cerveja exercer influência sobre a escolha da marca. Isso ocorre, segundo os autores, devido a significativa similaridade dos sabores de diversas marcas, que dificulta seu reconhecimento sem a presença de um rótulo.

Referente à comparação da influência da imagem da mulher entre os gêneros, percebeu-se que a influência que a figura feminina em comerciais de cerveja exerce sobre mulheres é inversa à influência que ela exerce sobre homens. Enquanto as mulheres tendem a rejeitar propagandas com imagens femininas, os homens as avaliam de forma positiva. Adicionalmente, notou-se que as propagandas que exibem homens tendem a ser mais bem avaliadas pelas mulheres.

Deve-se ressaltar que os resultados obtidos não podem ser transcendidos para toda a população de consumidores de cerveja, já que a ferramenta de coleta de dados foi aplicada a uma amostra não probabilística selecionada por conveniência. Diante dessa limitação, recomenda-se a realização de novas pesquisas sobre esse tema, utilizando-se uma amostra que torne possível a projeção dos resultados para todo o universo em estudo. Outro aspecto a ser mais bem explorado em futuras pesquisas é a influência da imagem masculina em comerciais e propagandas - tanto de cervejas quanto de outros produtos - sobre $o$ comportamento de compra dos consumidores, a fim de se comprovar a eficácia dessa forma de divulgação. Além disso, seriam de grande relevância pesquisas aprofundadas em outros aspectos responsáveis pela decisão de compra e consumo, alheios ao fator propaganda.

\section{Referências}

AAKER, J. Dimensions of brand personality.Journal of Marketing Research, [S.I], v.34, n.3, p.347-356, 1997.

AAKER, D. A; KUMAR, V; DAY, G. S. Pesquisa de marketing. 2. ed. São Paulo: Atlas, 2004.

ALLISON, R. I.; UHL, K. P. Influence of beer brand identification on taste perception. Journal of Marketing Research, [S.I], v. 1, n. 3, p. 36-39, 1964.

BELCH, G. E.; BELCH, M. A. Propaganda e promoção: uma perspectiva da comunicação integrada de marketing. 9. ed. Porto Alegre: AMGH, 2014.

BRANDÃO, E. A.; SOUKI, G. Q.; GONÇALVES FILHO, C.; MARTINS, H. C.; MUNIZ, R. M. A propaganda como estratégia de diferenciação no varejo: construção de uma escala baseada no modelo ARM.

Revista Ciências Administrativas, Fortaleza, v. 22, n. 2, p. 699-730, jul./dez. 2016.

CERVIERI JÚNIOR, O. et al. O setor de bebidas no Brasil. BNDES Setorial, Rio de Janeiro, n. 40, p. 93129, set. 2014.

CHURCHILL JR, G. A; PETER, J. P. Marketing: criando valor para os clientes. São Paulo: Saraiva, 2010.

COSTA, F. J.; CAVALCANTE, A. A.. Comportamento do consumidor de cerveja: proposta de uma tipologia baseada na imagem e nas intenções em relação à marca. Revista de Negócios, Blumenau, v. 12, n. 4, p. 71-85, out./dez. 2007.

CRUZ, S. U. A representação da mulher na mídia: um olhar feminista sobre as propagandas de cerveja. In: ENCONTRO DE ESTUDOS MULTIDISCIPLINARES EM CULTURA, 4., Salvador, 2008. Anais... Salvador: ENECULT, 2008.

FERRARI, V. O mercado de cervejas no Brasil. 2008. 131f. Dissertação (Mestrado em Economia) Pontifícia Universidade Católica do Rio Grande do Sul, Curso de pós-graduação em Economia, Porto Alegre, 2008.

BORGES, A.; CUNHA, J. Cerveja promove mulher de caça a caçadora em propaganda. Folha de São Paulo. São Paulo, 2015. Disponível em: <http://www1.folha.uol.com.br/mercado/2015/10/1689798marcas-de-cerveja-acordam-para-publico-feminino-e-mudam-comerciais.shtml>. Acesso em: 07. jun. 2016. 
G1. SABMiller aceita oferta de compra da AB InBev por US\$ 109 bilhões. 2015. Disponível em: <http://g1.globo.com/economia/negocios/noticia/2015/10/sabmiller-aceita-oferta-de-compra-da-ab-inbevpor-us-109-bilhoes.html>. Acesso em: 06 jun. 2016.

GOMES, R.; TOURINHO, F. S. T. O gênero propaganda e seus efeitos de sentido: uma análise a partir da teoria semiolinguística. Revista de Estudos Acadêmicos de Letras, Cáceres, v. 8, n. 1, p.170-185, jun. 2015.

GIL, A. C. Como elaborar projetos de pesquisa. 5. ed. São Paulo: Atlas, 2010.

GRANATO, A.; VILLELA, R.. Um ícone brasileiro. Veja, São Paulo, v. 32, n. 27,07 jul. 1999. p. 134-135.

GROHMANN, B. Gender dimensions of brand personality. Journal of Marketing Research, [S.I], v.46, n.1, p.105-19, 2009.

GUAZINA, S.; GUIMARÃES, I. P.. O super corpo negro: a representação do lutador anderson silva, no comercial The GreatPreparation, da cerveja Budweiser. Animus: Revista Interamericana de Comunicação Midiática, Santa Maria, v. 15, n. 29, p.124-144, 2016.

LEVINE, D. M. et al. Estatística: teoria e aplicações usando o Microsoft Excel em português. 6. ed. Rio de Janeiro: LTC, 2013.

HOOLEY, G.; PIERCY, N. F.; NICOULAUD, B. Estratégia de marketing e posicionamento competitivo. 4. ed. São Paulo: Pearson Prentice Hall, 2011.

IBOPE. Cerveja e vinho são as bebidas alcoólicas mais consumidas pelos internautas no Brasil. 2013. Disponível em: <http://www.ibope.com.br/pt-br/noticias/Paginas/Cerveja-e-vinho-sao-as-bebidasalcoolicas-mais-consumidas-pelos-internautas-no-Brasil.aspx>. Acesso em 01 jul. 2016.

KIM, L. J. "Beba à vontade, viva à vontade": estudo do reposicionamento da marca Aquarius Fresh visto pelo consumidor. 2010. 93 f. Monografia (Bacharel em Comunicação Social) - Universidade Federal do Rio Grande do Sul, Faculdade de Biblioteconomia e Comunicação, Porto Alegre, 2010.

KOTLER, P. Administração de marketing. 10. ed. São Paulo: Pearson Prentice Hall, 2000.

KOTLER, P.; ARMSTRONG, G. Princípios de marketing. 12. ed. São Paulo, SP: Pearson, 2007.

MALHOTRA, N. K. Pesquisa de marketing: uma orientação aplicada. 6. ed. Porto Alegre: Bookman, 2012.

MALTA, R. B.; SILVA, K. M. R. A atual representação da mulher em comercias de cerveja: relações socioculturais e mercadológicas. Verso e Reverso, São Leopoldo, v. 30, n. 73, p.50-57, jan./abr. 2016.

MOMO, M. V. G.; FRANCO, C. F. M. Sensualidade etílica: o estereótipo da mulher devassa na propaganda de cerveja. In: ENCONTRO NACIONAL DE HISTÓRIA DA MÍDIA, 9., Ouro Preto, 2013. Anais... Ouro Preto: ALCAR, 2013.

OLIVEIRA, I. M.; GONÇALVES, I. F. O comportamento do consumidor: o perfil e os hábitos de consumo de cerveja dos universitários de Marília. 2014. 44 f. Monografias de TCC (Graduação em Administração) - Centro Universitário Eurípides de Marília - UNIVEM, Curso de Administração, MaríliaSP, 2014.

OLIVEIRA, M. H.; MEDEIROS, L. A. R.; RIBEIRO, A. P. A. Cerveja. BNDS Setorial, Rio de Janeiro, v.10, n. 1 p. $1-5$, abr. 1996.

PETROLL, M. M.; ROSSI, C. A. V. Apelo sexual na propaganda e seus efeitos sobre o consumidor: um experimento em mídia impressa. Revista de Administração da USP, São Paulo, v. 1, n. 2, p.1-22, jul./ dez. 2008.

PLUMMER, J. How personality makes a difference. Journal of Advertising Research, [S.I], v. 40, n. 6,p.79-84, 2000. 
ROCKENBACH, M. R. P.A imagem feminina nas propagandas de cerveja. Gestão: Revista Científica de Administração, [S.I], v. 12, n. 12, p.31-42, jun. 2009.

ROMERO, D. Efeito da estratégia de preço de cerveja e vodca sobre o faturamento do ponto de venda. 2015. 49 f. Trabalho de conclusão de graduação (Graduação em Administração) - Universidade Federal do Rio Grande do Sul, Curso de Administração, Porto Alegre, 2015.

ROSA, S. E. S.; COSENZA, J. P.; LEÃO, L. T.S.. Panorama do setor de bebidas no Brasil. Bndes Setorial, Rio de Janeiro, v. 23, n. 1, p.101-150, mar. 2006.

SILVA, D. B.. Preferência por marcas de cerveja e situação de uso: um estudo com pós-graduandos em Administração em Salvador. 2008. 96 f. Dissertação (Mestrado em Administração) - Universidade Federal da Bahia, Curso de pós-graduação em Administração, Salvador, 2008.

SILVA, E. L.; MENEZES, E. M. Metodologia da pesquisa e elaboração de dissertação. 3 ed. Florianópolis: Laboratório de ensino a distância da UFSC, 2001.

SINDICERV. A cerveja. 2016. Disponível em: <http://www.sindicerv.com.br/acerveja.php>. Acesso em 01 jul. 2016.

SOLOMON, M. R. O Comportamento do consumidor: comprando, possuindo e sendo. 11. ed. Porto Alegre: Bookman, 2016.

TAGNIN, A. C. C. N.; GIRALDI, J. M. E. Atributos do produto valorizados no processo de decisão de compra de cerveja: um estudo qualitativo com universitários. Produto\& Produção, São Paulo, v. 14, n. 1, p. 84-106, fev. 2013.

URDAN, A. T.; URDAN, F. T. O impacto da marca sobre as preferências do consumidor: um experimento com cerveja. In: ENCONTRO ANUAL DA ANPAD , 25., 2001, Campinas, São Paulo. Anais... Campinas, São Paulo: ANPAD, 2001. p. 1-13 .

VERGARA, S. C. Projetos e relatórios de pesquisa em administração. 3. ed. São Paulo: Atlas, 2000.

WARMLING, K. R.; BARRAGAN, T. G. S. A mulher nas propagandas de cerveja: efeitos de sentido.

Revista Eventos Pedagógicos, [S.I], v. 3, n. 1, p. 227-235, abr. 2012.

Submetido em: 29/08/2016

Aprovado em: 20/11/2016 